\title{
ACESSO À JUSTIÇA E DESIGUALDADE SOCIAL: REFLEXOS NA EFETIVAÇÃO DOS DIREITOS FUNDAMENTAIS
}

\section{ACCESS TO JUSTICE AND SOCIAL INEQUALITY: REFLECTIONS ON THE EFFECTIVE OF FUNDAMENTAL RIGHTS}

\author{
1 Guilherme Barbosa da Silva \\ ${ }^{2}$ Amanda Querino dos Santos Barbosa
}

\begin{abstract}
Resumo
$\mathrm{O}$ acesso à justiça, assegurado constitucionalmente, não vem sendo aplicado de modo irrestrito a todos os cidadãos. A desigualdade econômica possui graves consequências também no processo civil. Assim, ainda que o novo CPC tenha trazido significativos avanços buscando maior efetividade e celeridade processual, como é o caso da arbitragem e mediação, verificase que tais hipóteses são de aplicabilidade mitigada, já que uma camada da população não possui recursos financeiros aptos a tais medidas. Pretende-se abordar o tema, analisando o conceito de acesso à justiça, bem como medidas para que possa ser efetivado.
\end{abstract}

Palavras-chave: Acesso à justiça, Desigualdade social, Desigualdade processual

\section{Abstract/Resumen/Résumé}

Access to justice, guaranteed constitutionally, has not been applied on an unrestricted basis to all citizens. Economic inequality has serious consequences also in civil proceedings. Thus, although the new CPC has brought significant advances seeking greater effectiveness and promptness, such as arbitration and mediation, it appears that such assumptions are mitigated applicability, since a portion of the population does not have financial resources capable of such measures. It is intended to address the issue, analyzing the concept of access to justice, as well as measures that can be made effective.

Keywords/Palabras-claves/Mots-clés: Access to justice, Social inequality, Procedural inequality

\footnotetext{
${ }^{1}$ Mestrando em Ciência Jurídica pela Universidade Estadual do Norte do Paraná, UENP - PR, (Brasil). E-mail: guilhermebarbosaadv@hotmail.com

${ }_{2}^{2}$ Mestranda em Ciência Jurídica pela Universidade Estadual do Norte do Paraná, UENP - PR, (Brasil). E-mail: amandaquerino@hotmail.com
} 


\section{INTRODUÇÃO}

Paira no seio social o sentimento de que a justiça - no sentido de busca pelo Poder Judiciário - só existe para aqueles que possuem esparsos recursos financeiros. De certo modo, tal pensamento pode ser considerado verdadeiro, uma vez que aqueles que possuem maiores recursos financeiros, com condições de buscar pela tutela jurisdicional através de um causídico devidamente constituído, sem necessidade de esperar do Estado a figura de um Defensor Público, ou mesmo a nomeação de um advogado dativo, realmente conseguem uma maior efetivação dos seus direitos.

Não que os doutos advogados nomeados, ou mesmo os defensores públicos, devidamente aprovados do concurso público, não possuam competência para tanto. Ocorre que é notório o déficit dos profissionais citados para que a demanda processual pudesse ser superada. Cite-se, por exemplo, o Estado do Paraná, que foi um dos últimos estados do Brasil a instituir a Defensoria Pública, e que, até o momento, não possui um defensor em cada Comarca do Estado para efetivar os anseios da população paranaense.

Assim, o presente trabalho pretende demonstrar que a pobreza, fator de discriminação na sociedade, é também fator de discriminação processual, ferindo a isonomia resguardada pela Constituição da República Federativa do Brasil. Deste modo, no primeiro capítulo deste trabalho, pretende-se demonstrar o quão fundamental é o acesso à justiça para a efetividade dos demais direitos dispostos no texto constitucional de 1988. Traçar-se-á um breve histórico acerca do direito suscitado, desde seu nascedouro até as constituições brasileiras mais modernas, finalizando com a análise do atual Texto Maior. Pretende-se, ainda no primeiro capítulo, tornar o conceito de "acesso à justiça" - muito embora haja grande dificuldade de definição própria - mais claro aos pesquisadores, demonstrando que o direito aqui analisado, na verdade se trata de um direito supranacional.

Na sequência, no segundo capítulo, serão abordados alguns fatores que levam a parcela mais vulnerável da sociedade, aqueles considerados mais necessitados, economicamente, também vulneráveis processualmente. Buscar-se-á analisar o que é considerado "minoria", para que assim seja, efetivamente analisada se os cidadãos com renda mínima podem ser considerados "minorias".

Por fim, no terceiro e último capítulo, será analisada como essa pobreza, esse fator que faz com que o princípio da isonomia seja desrespeitado em diversos setores da sociedade, atinge também a demanda processual e exclui uma grande parcela da sociedade da efetiva proteção 
jurisdicional, uma vez que há efetiva exclusão processual. Assim, pretende a pesquisa aqui proposta,, uma reflexão sobre alguns bloqueios à concretização do acesso à justiça, obstruindo um sistema que traz importantes impactos à sociedade .

\section{ACESSO À JUSTIÇA COMO DIREITO FUNDAMENTAL}

$\mathrm{Na}$ atual sistemática do Direito brasileiro, compete, quase que exclusivamente, ao Estado a função da resolução de conflitos, por meio de um de seus poderes, o Poder Judiciário. Entretanto, é possível verificar que, assim como os outros poderes da república, e demais órgãos como um todo, e não seria diferente com o órgão jurisdicional, o Poder Judiciário vem passando por uma profunda crise de legitimidade, já que não consegue colocar fim aos tantos conflitos da sociedade. Sobre a necessidade de algumas mudanças para que o Poder Judiciário venha acompanhar as alterações da sociedade como um todo, José Luiz Bolzan de Morais sustenta que

[...] os acontecimentos deste século repercutiram em fatos determinantes de profundas mudanças nas relações sociais, o que se refletiu na situação atual, onde ao Judiciário impõem-se reformas, para atender as exigências sociais contemporâneas. Afinal, até o momento, o mesmo tem resguardado para si uma postura de superioridade, ignorando todos esses fatos novos e considerando as relações sociais como as considerava no início do século (MORAIS, 1999, p. 78).

É certo que a figura do Poder Judiciário, principalmente com o advento da Constituição da República Federativa do Brasil de 1988, possui um caráter fundamental na manutenção e resguardo dos direitos elementares dos cidadãos. Entretanto, conforme o autor acima citado, é preciso que o Poder Judiciário crie mecanismos para efetivar os direitos que são tutelados pelas partes.

A tutela jurisdicional buscada pelos cidadãos gera uma grande segurança jurídica aos mesmos. Entretanto, o Estado não cumprindo com sua missão, determinada pela Constituição Federal, de prestar a proteção referida torna essa segurança numa incerteza, e traz descrédito à justiça brasileira. O que se busca não é o retorno à autotela que há muito tempo foi extirpada da sociedade moderna como regra geral, permanecendo em casos excepcionais. Ocorre que para que isso não venha ocorrer, o Estado deve proporcionar uma maior efetivação do acesso à justiça.

Assim, o presente capítulo pretende demonstrar que o acesso à justiça, muito mais que um direito fundamental, é um direito apto a resguardar outros direitos, razão pela qual, 
imperiosa uma alteração da forma de atuação do Poder Judiciário, para que este direito não seja transformado num obstáculo processual.

\subsection{Breves Aspectos Históricos Acerca do Direito Fundamental do Acesso à Justiça}

Para melhor análise deste direito fundamental é preciso realizar uma concisa análise histórica da ideia de acesso à justiça. $\mathrm{O}$ ideal de acesso à justiça que se tem hoje, não é o mesmo que se tinha em tempos passados. Vinícius José Corrêa Gonçalves aborda que

[...] num primeiro momento, com o surgimento do Estado Liberal no final do século XVIII e início do século XIX, „, direito ao acesso à proteção judicial significava essencialmente o direito formal do indivíduo agravado de propor ou contestar uma ação "e. Assim, nesse período, o acesso à justiça não passava de um mero direito formal, tendo o Estado a simples função de positivá-lo no ordenamento, pois se mantinha inerte frente às desigualdades observadas no plano empírico (GONÇALVES, 2011, P. 26).

Note-se, então, que num primeiro momento tal direito não era considerado um direito propriamente material, mas sim direito formal, colocado nas mãos dos cidadãos, que eram lançados à sorte para efetivá-lo. O direito de acesso à justiça era considerado um direito natural, e como tal, não necessitava de uma ação do Estado para que fosse protegido, já que tais direitos eram considerados anteriores ao surgimento do Estado. Assim, bastava que o Estado não permitisse a infringência deste direito por outros (CAPPELLETTI et al, 1998, p.9).

Desta feita, conforme o apontado linhas acima, denota-se que somente uma parcela da sociedade, aquela que detinha melhores condições financeiras, possuía meios para se valer e tornar verdadeiramente efetivo este acesso à justiça.

É possível relacionar o pensamento contemporâneo do acesso à justiça com a ideia da primeira dimensão dos direitos fundamentais, onde cabe ao Estado simplesmente uma limitação, um não agir, e não a criação de mecanismos para uma efetivação. Assim, tendo em vista que somente uma parte da população possuía o efetivo acesso à justiça, o Estado passa a perceber que não basta uma não intervenção somente, mas que é preciso uma atuação para que este direito possa ser efetivado.

Surge então o que foi denominado como direitos fundamentais de segunda dimensão, com a criação dos direitos sociais, saindo o Estado daquela situação de impassibilidade, tomando caráter de garantidor. Nasce o Estado Social, onde as liberdades públicas cedem espaço aos direitos sociais, sempre os pautando na igualdade de condições e oportunidades. O Estado 
passa a ser intervencionista, e quando não age cabe ao indivíduo incitá-lo, por meio do Poder Judiciário, surgindo, também, o direito da demanda judicial.

Norberto Bobbio aduz que "o princípio da igualdade foi o motor das transformações nos conteúdos e declarações, abrindo sempre novas dimensões aos direitos humanos" (BOBBIO et al, 2004). Assim, pode-se afirmar que o tal princípio foi o norte da evolução da ideia de acesso à justiça que hoje vigora. Acerca do marco fundamental para a nova vertente do acesso à justiça, Adriana Santos Silva afirma:

\begin{abstract}
Com as transformações da sociedade, houve também a mudança paradigmática do acesso à Justiça, havendo necessidade de tornar efetiva com a valorização do caráter coletivo em detrimento do caráter individualista antes sistematizado. $\mathrm{O}$ marco desse acontecimento deu-se com a Declaração dos Direitos Humanos. [...] Quando se fala em acesso à Justiça, o objetivo direto é tornar efetivo um dos principais e fundamentais direitos do cidadão: o de garantir seus direitos e não apenas garantir sua propositura (SILVA, 2005, p. 96).
\end{abstract}

No Brasil, já na primeira constituição republicana ficou consagrada a tripartição dos Poderes, restando ao Poder Judiciário a incumbência de colocar fim nos conflitos. Entretanto, foi somente com a Constituição de 1946 que a acessibilidade ampla foi expressamente consagrada, já que seu art. $141, \S 4^{\circ}$ dispunha que: “A lei não poderá excluir da apreciação do Poder Judiciário qualquer lesão de direito individual". Todavia, durante o período de vigência do Ato Institucional $\mathrm{n}^{\circ} 5$, todos os atos praticados com base naquele ato foram excluídos de apreciação do Judiciário, o que acabou limitando o acesso à justiça.

Após o período de limitação dos direitos fundamentais e, principalmente, com o advento da Constituição Federal de 1988, o princípio da inafastabilidade do judiciário volta a permear os direitos dos cidadãos. Ressalta-se que, incluído dentre os direitos e deveres fundamentais dos indivíduos, art. 5, XXXIV, $a$, da Constituição Federal, tal direito é considerado cláusula pétrea e, durante a vigência da atual Constituição, não poderá ser extirpado do ordenamento jurídico.

Assim, estreme de dúvidas que o acesso à Justiça sofreu profundas transformações, já que hoje a ideia de acesso à justiça é muito mais que um mero direito formal, mas sim um direito material, ou ainda, como será abordado abaixo, um direito instrumental, já que através do acesso à justiça o cidadão pode buscar a tutela dos seus demais direitos fundamentais.

Mas afinal, o que é acesso à justiça? Qual o real e atual significado dessa expressão que permeia documentos nacionais e internacionais? Definindo objetivamente, Mauro Cappelletti e Bryant Garth explanam que 


\begin{abstract}
A expressão „acesso à Justiça“ é reconhecidamente de difícil definição, mas serve para determinar duas finalidades básicas do sistema jurídico - o sistema pelo qual as pessoas podem reivindicar seus direitos e/ou resolver seus litígios sob os auspícios do Estado. Primeiro, o sistema deve ser igualmente acessível a todos; segundo, ele deve produzir resultados que sejam social e individualmente juntos (CAPPELLETTI et al, 1998, p. 8).
\end{abstract}

Heliana Coutinho Hess conceitua o acesso à Justiça como um direito fundamental supranacional, afirmando que

\begin{abstract}
Direito porque está inserido no sistema jurídico-constitucional do Estado. Fundamental porque deve ser reconhecido como intrínseco ao homem pelas autoridades do país, tanto o Poder Legislativo que edita normas, o Judiciário que aplica no plano fático, quanto o Executivo que tem a obrigação de realizar políticas públicas, respeitada a dignidade humana, como valor universal e ético. Supranacional porque reconhecido nos ordenamentos jurídicos internados por leis do Estado, no plano supranacional, dos blocos de países, e internacional por tratados e pactos de direitos humanos, concretizado pelo exercício da jurisdição pública e privada (HESS, 2004, p. $5)$.
\end{abstract}

Veja que hoje incumbe, não somente ao Poder Judiciário, a efetividade do direito ao acesso à Justiça, mas a todos os Poderes da República. Pode-se afirmar, inclusive, que o Ministério Público também se mostra como um instrumento indispensável para a efetivação deste direito, através do atendimento ao público, que, desamparado, tem no Promotor de Justiça aquele que pode resolver o seu problema, ou, ao menos, colaborar para a resolução. Vale lembrar que a Constituição Federal de 1988 ressalta a importância do Parquet para o Estado democrático, ao passo que o considera, em seu artigo $127^{1}$, uma "instituição permanente e essencial à função jurisdicional do Estado".

Quando se afirma que o acesso à justiça se trata de um direito fundamental supranacional, percebe-se que realmente este direito encontra-se amparado em diversos documentos internacionais. O Pacto de San José da Costa Rica, por exemplo, que foi incorporado ao direito brasileiro por intermédio do Decreto $n^{\circ}$ 678, aprovado em 06 de novembro de 1992, dá ao indivíduo a possibilidade de ser ouvida em juízo, num prazo que seja considerado razoável ${ }^{2}$. Impõe, ainda, que o juiz ou Tribunal deva ser imparcial e independente. Assim, resta claro que hoje a ideia de acesso à Justiça não significa a atuação

\footnotetext{
1 Art. 127. O Ministério Público é instituição permanente, essencial à função jurisdicional do Estado, incumbindo-lhe a defesa da ordem jurídica, do regime democrático e dos interesses sociais e individuais indisponíveis.

2 Artigo $8^{\circ}$ - Garantias judiciais. Toda pessoa terá o direito de ser ouvida, com as devidas garantias e dentro de um prazo razoável, por um juiz ou Tribunal competente, independente e imparcial, estabelecido anteriormente por lei, na apuração de qualquer acusação penal formulado contra ela, ou na determinação de seus direitos e obrigações de caráter civil, trabalhista, fiscal ou de qualquer outra natureza.
} 
exclusiva do Poder Judiciário, mas sim, qualquer meio que possa solucionar os conflitos de maneira equânime e justa, com eficiência buscando sempre a dignidade da pessoa humana.

Entretanto, ocorre que, mesmo não sendo somente por atuação do Poder Judiciário que se vê a efetivação do acesso à Justiça, tal ente ainda é o que mais vem sendo buscado para tutelar os direitos fundamentais dos cidadãos, razão pela qual imperioso se faz observar alguns pontos importantes acerca dessa atuação, conforme será abordado em tópicos ulteriores ${ }^{3}$. Cita-se, também, o pensamento de Mauro Cappelletti e Bryant Garth que entendem ser $\mathrm{o}$ acesso à justiça um requisito fundamental do atual sistema jurídico que pretenda garantir efetivamente o direito de todos. Complementam que "o ,acesso ce não é apenas um direito social fundamental, crescentemente reconhecido, ele é, também, necessariamente, o ponto central da moderna processualística. Seu estudo pressupõe um alargamento e aprofundamento dos objetivos e métodos da moderna ciência jurídica" (CAPPELLETTI et al, 1998, p. 13).

Hoje, o acesso à Justiça é considerado um direito fundamental instrumental, já que visa assegurar a efetividade dos demais direitos fundamentais. Conforme exposto, o direito de acesso à justiça não está mais adstrito ao significado de judiciário, o que ocorria em tempos outros quando as duas expressões eram tidas como sinônimas. Gelson Amaro de Souza aduz que

\footnotetext{
Tornou-se comum confundir-se o acesso à justiça com o simples acesso ao judiciário. Sem a efetiva entrega do direito à parte que o merece, não se pode dizer que direito de ação, puro e simples, já representa o acesso à justiça. Estas expressões não devem ser confundidas, como não se devem confundir a tutela jurídica com a tutela jurisdicional e nem esta com a tutela do direito. $\mathrm{O}$ acesso à justiça e a efetivação do direito somente acontecem quando for concretamente empreendida a tutela do direito, isto é, a proteção ou a efetivação do direito material (SOUZA et al, 2012, p. 212).
}

Para o autor supracitado, o efetivo acesso à justiça se dá com o julgamento de mérito e a satisfação do direito reconhecido, ainda que o autor da demanda saia vencido. Caso contrário, "pode ter havido acesso ao Judiciário, mas não acesso à justiça" (SOUZA et al, 2012, p. 212). Daniela Dias Graciotto Martins, por sua vez, demonstra que não se pode confundir o direito à tutela jurisdicional com o direito à petição:

O direito de ação por sua vez, requer o preenchimento das condições de ação, consistentes no interesse processual, na possibilidade jurídica do pedido e na legitimação da parte. Não havendo o preenchimento destes requisitos (art. 267, VI, CPC), bem como dos pressupostos processuais (art. 267, IV, CPC), a ausência da análise do mérito não ofende o princípio da inafastabilidade de jurisdição. $\mathrm{O}$ acesso à justiça não significa, ainda, a procedência do pedido. O que se assegura é a tutela jurisdicional adequada (MARTINS, 2012, p. 92).

\footnotetext{
3 Vide capítulo 3 deste artigo.
} 
Muito embora os dispositivos citados pela autora façam menção ao Código de Processo Civil de 1973, percebe-se que se adequa perfeitamente ao que atualmente vigora, tendo em vista a aprovação do novo Código de Processo Civil em 2015, uma vez que as hipóteses de não resolução do mérito pelo magistrado, hoje dispostas no art. 485, guardam estreita relação com o anteriormente vigorava.

Gelson Amaro de Souza, já citado anteriormente, com posição contrária ao da autora supracitada, complementa que

Só existe acesso à justiça quando o mérito é apreciado. O mérito como se sabe, corresponde ao pedido. Muito clara é a exposição de motivos ao dizer que o julgamento do conflito de pretensões, mediante o qual o juiz, acolhendo ou rejeitando o pedido, dá razão a uma das partes e nega-a a outra, constitui uma sentença definitiva de mérito (SOUZA et al, 2012, p.239).

Para o autor se o juiz deixar de apreciar o mérito da causa acaba deixando de apreciar o direito material reclamado, fechando as portas do acesso à justiça (SOUZA et al, 2012, p. 239). O autor entende, ainda, que quando a norma infraconstitucional impõe alguns pressupostos para que o pedido seja analisado, isto também ofende o acesso à justiça. Explana que

[...] existem normas que determinam a extinção do processo sem julgamento como a mais expressiva constante do art. 267, do CPC, que impede a apreciação do mérito, sempre que faltar algumas das condições da ação ou algum pressuposto processual. Essa norma, à toda evidência, está impedindo o acesso à justiça, em afronta à norma constitucional estatuída no art. $5^{\circ}, \mathrm{XXXV}$ da CF. A extinção do processo sem julgamento do mérito, não atende ao mandamento constitucional do art. $5^{\circ}, \mathrm{XXXV}$, da $\mathrm{CF}$, porque nada está decidindo e deixando de apreciar a lesão ou ameaça de lesão do direito (SOUZA et al, 2012, p. 239-240).

Para o autor é somente a decisão de mérito, ainda que o autor da demanda possa não receber uma sentença procedente, que efetiva o direito de acesso à justiça. Entretanto, atualmente o acesso à justiça é muito mais que mover a máquina judiciária, mas sim, a busca pela tutela jurisdicional adequada, que compete ao Estado conceder, através das técnicas necessárias, para que o direito material não seja violado.

Vinícius José Corrêa Gonçalves aborda que o direito ao acesso à justiça é denominado "direito fundamental instrumental", já que é por meio dele que todos os demais direitos poderão ser tutelados, complementando que

[...] a negação do direito fundamental de acesso à justiça pode ser encarada como a negação a todos os demais direitos fundamentais insculpidos no ordenamento jurídico pátrio, pois uma vez ameaçados ou violados tais direitos, sem a possibilidade de se efetuar o acesso à justiça [...] seus detentores quedariam inertes e sem meios de promover a sua defesa, já que, em regra, é vedada a utilização da autotutela (GONÇALVES, 2011, p. 35). 
Ocorre que, em que pese a inexistência, no atual sistema brasileiro, da autotutela, não há como negar que este é um dos efeitos colaterais da inefetividade do acesso à justiça.

\section{EXLUSÃO E DESIGUALDADE SOCIAL}

Como já analisado, há diversos fatores que acabam excluindo uma parcela da população da efetividade do acesso à justiça. Cite-se, como exemplo - uma vez que tema será melhor analisado em momento oportuno -, o ônus financeiro do processo como sendo um dos fatores que acabam diminuindo o interesse do cidadão de buscar a resolução para o seu conflito através do Poder Judiciário.

Entretanto, é preciso definir a priori, quais as parcelas da sociedade estão sendo colocadas à margem do direito. Afinal, o que se entende por as minorias? O termo "minorias" carece de uma definição precisa, muito menos legal. Todavia é preciso compreender que compete ao Estado a busca de meios para que os grupos que possuam este sentimento de inferioridade possam efetivar seus direitos. J. J. Canotilho ao conceituar minoria, aduz que

\footnotetext{
Minoria será, fundamentalmente, um grupo de cidadãos de um Estado, em minoria numérica ou em posição não dominante nesse Estado, dotado de características étnicas, religiosas ou linguísticas que diferem das da maioria da população, solidários uns com os outros e animados de uma vontade de sobrevivência e de afirmação da igualdade de facto e de direitos com a maioria (CANOTILHO, 2003, p. 387).
}

Verifica-se, então, que a ideia de minoria não está atrelada necessariamente a uma porção inferior a outra. Pode-se considerar minoria um grupo numérico em posição inferior a outro, bem como outras características individuais que inferiorizam tais indivíduos. Todavia os efeitos são os mesmos: tais pessoas enfrentam maiores dificuldades dentro do Estado e necessitam de maior efetividade de seus direitos mínimos.

O presente estudo será pautado na minoria considerada menos favorecida, aquela que possui condições financeiras mínimas e a (in)efetividade do acesso à justiça. Pode-se afirmar que a pobreza é uma das consequências do mundo globalizado. Após o final do século XX e no início do século XXI, o fenômeno da pobreza sofreu alterações no mundo todo, entretanto, pode-se afirmar que ainda há muito a ser feito para que a desigualdade possa começar a ser alterada. Pedro Demo expõe que

A estrutura da desigualdade permanece intacta, mas, em compensação, os pobres estão um pouco menos pobres, um resultado típico do atual programa Bolsa Família: é 
adequado no plano da assistência, porque é devida por direito; é inadequado no plano do confronto político, porque o abafa. Os pobres são tão pobres que qualquer migalha interessa, e com esse preço vendem facilmente a alma (DEMO, 2006, p. 82).

Data vênia o posicionamento acima, não parece acertada as palavras do autor quando afirma que "qualquer migalha interessa" ou que os mesmos "vendem facilmente a alma". Certo é que a desigualdade impera no país, e o programa de distribuição de renda citado visa, de certa forma, atenuar tal diferença. Todavia, tal ponto não é crucial para análise desta pesquisa. Assim, necessário concluir apenas que, em que pese os avanços contemporâneos, a desigualdade social continua a vigorar.

Ao andar pelas ruas é possível visualizar desigualdade social, onde muitas e muitas pessoas encontram-se em condições de extrema pobreza. Em todos os centros é possível encontrar pessoas nas ruas buscando o sustento para o seu dia, através de poucas moedas lhes dadas no semáforo.

Convém destacar que a Constituição impõe como um de seus fundamentos a erradicação da pobreza e a redução das desigualdades sociais e regionais ${ }^{4}$. Ocorre que atualmente a redução da desigualdade não é sinônimo de distribuição de renda somente. Proporcionar aos cidadãos um efetivo acesso à justiça também faz com que as desigualdades sociais sejam amplamente reduzidas. É nítido que o Brasil vem apresentando enorme desigualdade na distribuição de renda, o que acaba gerando uma elevação nos níveis de pobreza.

O termo pobreza não pode ser definido de forma universal. Todavia, é possível afirmar que se trata de uma situação de carência em que o indivíduo não possui condições para manter um padrão mínimo de vida que seja condizente com o mínimo existencial, de acordo com o que é estabelecido socialmente em cada contexto histórico. Sônia Rocha conceitua:

Pobreza é um fenômeno complexo, podendo ser definido de forma genérica como a situação na qual as necessidades não são atendidas de forma adequada. Para operacionalizar essa noção ampla e vaga, é essencial especificar que necessidades são essas e qual nível de atendimento pode ser considerado adequado. A definição relevante depende basicamente do padrão de vida e da forma como as diferentes necessidades são atendidas em determinado contexto socioeconômico (ROCHA, 2003, p. 9).

\footnotetext{
${ }^{4}$ Vide artigo 3을 III, da Constituição da República Federativa do Brasil de 1988.
} 
Assim, pode-se afirmar que há pobreza quando famílias vivem com renda familiar per capita inferior ao nível mínimo necessário para que possam satisfazer suas necessidades básicas para se adequar ao grupo social em que vivem. A pobreza é vista como decorrência da ação dos homens, como resultado daquilo que pensam, interpretam e agem. Assim, a pobreza decorre da desigualdade social. A desigualdade e a pobreza sempre fizeram parte da construção histórica do país. Por diversas vezes esteve nas pautas de discussão. Todavia, não se vislumbra ações efetivas para enfrentar o problema. Ronaldo Coutinho Garcia aduz que

[...] foram criadas riqueza e renda suficientes para produzir alterações significativas nas condições de vida da grande massa da população brasileira que é carente de tudo. No entanto, a riqueza existente, a produzida e a renda criada sempre foram apropriadas concentradamente por minorias que sofrem de um estado crônico de „ganância infecciosa $^{\text {ee }}$ (GARCIA, 2003, p. 10).

É de competência do Estado regular a situação através de políticas públicas que proporcionem a diminuição da desigualdade. Sabe-se que "o mito da „cultura da pobrezaee, segundo o qual os pobres não melhoram suas condições de vida porque não querem, desfazse, sempre na dura frieza das evidências empíricas e históricas" (ABRANCHES, 1998, 16). O que se percebe é que pouco foi modificado durante o processo de desenvolvimento do Brasil, apesar de muito se estudar e discutir acerca do tema. Ocorre que, muito embora algumas inovações com a aprovação do novo Código de Processo Civil (2015), o fenômeno da pobreza atinge também o Poder Judiciário, mais especificamente a possibilidade de se efetivar a justiça daqueles menos favorecidos, conforme será exposto no próximo capítulo.

\section{OS REFLEXOS DA DESIGUALDADE SOCIAL NO PROCESSO CIVIL}

Como visto, a pobreza de uma grande parcela da sociedade faz com que a desigualdade vigore em diversos setores da Administração Pública. Infelizmente, esta desigualdade também vem acarretando a limitação dos direitos das pessoas com menores condições financeiras. Ocorre que a população, e principalmente aquela parcela excluída da sociedade, ainda enxerga o Poder Judiciário como o principal meio de se efetivar o acesso à justiça. Assim, é preciso que o Judiciário esteja totalmente estruturado para que a população não se sinta desprivilegiada.

Ainda que o novo Código de Processo Civil tenha trazido importantes avanços para a celeridade processual e efetivação da justiça, como por exemplo, a possibilidade expressa de 
resolução de um conflito através da mediação e arbitragem, certo é que tal resolução paira coerente e aplicável somente àqueles que possuem recursos financeiros mais altos, tendo em vista os elevados custos para aplicação das medidas inovadoras.

Todavia, ainda que tais medidas sejam, em tese, possíveis de serem aplicadas, é preciso lembrar das palavras de Cândido Rangel Dinamarco quando afirma que "no Estado de Direito, é nos juízes que a população deposita as suas mais acalentadas, as suas últimas esperanças de Justiça. Infelizmente, muitos têm ficado na decepção, pois os juízes são parte de um mecanismo que clama por restauração" (DINAMARMO, 1987, p. 14), o que é perfeitamente possível se comprovar.

Em uma pesquisa de opinião divulgada pelo Instituto Brasileiro de Opinião Pública e Estatística - IBOPE no ano de $2009^{5}$, ficou demonstrado que parte da população brasileira ainda possui um certo grau de confiança no Poder Judiciário. Foram entrevistadas 2002 pessoas de todas as regiões do país, chegando ao resultado de que $45 \%$ da população tem "alguma confiança" no Poder Judiciário e $16 \%$ possui "muita confiança" na instituição. Por sua vez $20 \%$ possui "quase nenhuma confiança”, enquanto $18 \%$ possui "nenhuma confiança".

Percebe-se nitidamente que o Judiciário ainda é aquele em que os indivíduos vêem a possibilidade de amparo, já que, de acordo com a mesma pesquisa, em se tratando do Congresso Nacional o índice cai para $31 \%$ para "alguma confiança" e 5\% para "muita confiança". E sobe quando a resposta é "quase nenhum confiança" atingindo $26 \%$, e $35 \%$ para a resposta "nenhuma confiança”. Entretanto, em que pese uma pequena diferença em se tratando de dois dos três Poderes, percebe-se que a diferença é tênue, o que demonstra que o Poder Judiciário também não vem cumprindo com o dever imposto pela Constituição Federal de 1988.

Não se pode negar que a população tem enxergado, ainda, o Poder Judiciário como um dos poderes que governam o país. Os diversos acontecimentos políticos que vêm marcando o cenário brasileiro faz com que a sociedade, na ânsia de ver a corrupção aniquilada, espere por uma resposta efetiva do Poder Judiciário, o enxergando, assim, como o principal meio de acesso à justiça, já que a resposta pela indisciplina também pode ser considerada acesso à justiça.

\footnotetext{
5 Disponível em $<$ http://www.ibope.com.br/ptbr/conhecimento/relatoriospesquisas/Lists/RelatoriosPesquisaEleitoral/OPP\%20090979\%20\%20Confian\%C3\%A7a\%20em\%20institui\%C3\%A7\%C3\%B5es.pdf >.
} 
O Judiciário vem sendo colocado pela mídia no centro das discussões, assim como os demais Poderes já estavam há muito tempo. Assim, deve tal órgão se ver preparado para dar as respostas necessárias à sociedade, efetivando seus direitos, já que o Judiciário ainda é considerado o manto protetor da população.

Assim, como primeiro ponto importante para a discussão da desigualdade processual, pode-se pautar a deficiência estrutural que o Poder Judiciário vem sofrendo, principalmente quando se trata do primeiro grau de jurisdição. Sabe-se que o Judiciário foi criado para atender um sistema capitalista e burguês, dirimindo conflitos de interesses individuais. Entretanto, o que se percebe que é outros tipos de conflitos também estão sendo levados ao judiciário para uma solução, tais como aqueles de interesses metaindividuais, envolvendo direitos difusos e, ainda, conflitos envolvendo pequenos litígios, com pouca importância pecuniária.

É certo que o Poder Judiciário durante muito tempo não recebia o tratamento merecido, e foi considerado um pouco menos importante em se tratando dos três poderes. Nesta esteira, Clóvis Ramalhete, ex-ministro do Supremo Tribunal Federal se manifestou afirmando que "jamais os constituintes republicanos, depois de adotarem o presidencialismo e a Federação, deram-se conta de que o Poder Judiciário é a ,chave do regime presidencial ${ }^{e}$, e, por consequência, deve ser autônomo e forte” (LYRA, 1986, p. 121). Daniela Dias Graciotto Martins aduz que

O advento do Estado social gerou o aumento da demanda judicial, pela omissão dos Poderes Legislativo e Executivo nas ações decorrentes do novo perfil estatal e, consequentemente, um conflito entre os próprios Poderes. Com o Estado Constitucional, e a figura do controle de constitucionalidade o conflito se acentuou. Por este controle, atos do Executivo e do Legislativo são submetidos ao crivo da Constituição, que em alguns sistemas, como o brasileiro, é personificada no Poder Judiciário, surgindo a „Jurisdição Constitucional“ (MARTINS, 2012 p. 95).

Percebe-se um grande número de demandas perante o judiciário, já que hoje é concentrado neste Poder o poder/dever de julgar os conflitos em tela. Todavia, ao que parece, o sistema estrutural do judiciário é dos tempos de outrora, o que acarreta na inefetividade da jurisdição. A autora complementa, afirmando que

[...] neste contexto histórico, as falhas estruturais da instituição do Poder Judiciário não preparada para atender às necessidades emergentes da nova ordem social - levou a uma crise do Direito. Este, ao ter alterado o seu centro de gravidade, não identificou prontamente sua verdadeira essência (MARTINS, 2012, p. 95). 
Hoje a importância do Poder Judiciário se mostra cada vez mais forte. Todavia é preciso uma reestruturação para que as demandas levadas a tal poder não careçam de efetividade e os direitos fundamentais venham ser limitados por ineficácia do Estado.

Como consequência da falta de estrutura do Poder Judiciário, é possível citar, ainda como (in)efetividade do acesso à justiça, a morosidade processual, já que atualmente o Judiciário não vem suportando atender a demanda processual existente. Verifica-se que o número de juízes ativos é, e muito, incompatível com a quantidade de processos aptos a julgamento. É evidente que quando se tem uma estrutura deficiente o resultado da prestação jurisdicional será de qualidade inferior, já que não possui os subsídios necessários para melhor decidir, o que faz com que os processos tramitem por tempo superior ao necessário para a resolução da lide. Em se tratando dos processos em trâmite por tempo ultrapassado, Rui Barbosa explana

\begin{abstract}
Mas justiça atrasada não é justiça, senão injustiça qualificada e manifesta. Porque a dilação ilegal nas mãos do julgador contraria o direito escrito das partes, e, assim, as lesa no patrimônio, honra e liberdade. Os juízes tardinheiros são culpados, que a lassidão comum vai tolerando. Mas sua culpa tresdobra com a terrível agravante de que o lesado não tem meio de reagir contra o delinquente poderoso, em cujas mãos jaz a sorte do litígio pendente (BARBOSA, 1997, p. 40).
\end{abstract}

E, por fim, adverte: "Não sejais, pois, desses magistrados, nas mãos de quem os autos penam como as almas do purgatório, ou arrastam sonos esquecidos como as preguiças do mato" (BARBOSA, 1997, p. 40).

Conforme se verifica a atual situação processual brasileira, a longa tramitação dos processos judiciais pode ser uma das causas da inefetividade do acesso à justiça, muito mais do que isso pode, inclusive, ser causa de uma injustiça social. Percebe-se que essa morosidade da jurisdição traz como consequência uma restrição ao exercício da cidadania a uma parcela da sociedade que se vê às margens do direito, já que não possui estímulos para buscar a tutela judicial na efetividade de seus direitos. Gelson Amaro de Souza aborda que

\footnotetext{
Muitas vezes se tem o acesso ao judiciário, como se fosse o verdadeiro acesso à justiça. Mas, o simples acesso ao Judiciário não pode ser considerado acesso à justiça. Ao contrário do ingresso junto ao Poder Judiciário que é a entrada, o acesso à justiça é a saída, com o direito satisfeito. Ingressar no Judiciário é até certo ponto fácil, o difícil é ter acesso à justiça. Isto é, sair do processo com a pretensão satisfeita dentro de um lapso de tempo razoável (AMARO et al, 2012, p. 233-234).
}

Hoje, o que se deve buscar não é a ampliação dos direitos fundamentais. Basta, tão somente, vencer o desafio de tornar efetivos os direitos já garantidos pelo texto constitucional, 
torná-los efetivos. Há que citar, ainda, a estrutura física dos gabinetes e secretarias, que não possuem o mínimo necessário para uma efetiva tutela aos jurisdicionados, o que causa um abismo entre o Poder Judiciário e o cidadão carente de seu direito violado. Almir Gallassi afirma

A morosidade gera descrédito, prejudica não só a imagem do Poder Judiciário, mas retira da pessoa humana o desejo de buscar uma solução para seu conflito. Se o problema é recurso financeiro, o Estado tem o dever de resolver, afinal, o cidadão contribui diariamente com impostos para que possa ter o retorno dessa contribuição através de uma prestação de serviço que deve ser oferecido pelo Estado (GALASSI, 2012, p. 6).

O Poder Legislativo e, principalmente, o Poder Executivo carecem de legitimidade quando se trata de colocar à disposição dos cidadãos mecanismos para efetivar seus direitos. A ausência da efetividade do direito à saúde, educação, saneamento básico, os direitos vitais mínimos, faz com que o indivíduo desacredite na Administração Pública, já que habitualmente arca com seus impostos e, em contrapartida, não consegue alcançar a efetividade dos seus direitos.

A morosidade do Judiciário também faz com que os cidadãos desacreditem neste poder, e pelos mesmos motivos esposados acima. Note-se que numa demanda processual, principalmente quando as partes, ou ao menos uma das partes, são hipossuficientes, o tempo é crucial, haja vista a necessidade de efetividade do direito tutelado para a manutenção do bem estar social, bem como o enorme custo que a morosidade traz ao processo.

Poderia ser citado ainda como limite ao acesso à justiça os elevados valores a título de custas processuais e ausência de uma defesa técnica digna aos menos favorecidos, já que não possuem condições de arcar com os custos de um advogado com técnica tão boa quanto da parte contrária. Entretanto, tal tema pode ser objeto de uma pesquisa em específico, já que é preciso realizar a análise à luz da Lei 1.060 de 1950, bem como da existência de Defensoria Pública em quase todos os Estados da Federação, apesar de deficiente, na maioria deles.

Tamanha a desigualdade durante toda a história da humanidade que o Papa Leão XIII, quando da publicação da Encíclica Rerum Novarum (15 de maio de 1591) já entendia ser necessário o tratamento desigual para que os direitos fossem efetivados:

\footnotetext{
Os direitos, em que eles se encontram, devem ser religiosamente respeitados e o Estado deve assegurá-los a todos os cidadãos, prevenindo ou vingando a sua violação. Todavia, na protecção dos direitos particulares, deve preocupar-se, de maneira especial, dos fracos e dos indigentes. A classe rica faz das suas riquezas uma espécie de baluarte e tem menos necessidade da tutela pública. A classe indigente, ao contrário, sem riquezas que a ponham a coberto das injustiças, conta principalmente com a protecção do Estado. Que o Estado se faça, pois, sob um particularíssimo título, a providência dos trabalhadores, que em geral pertencem à classe pobre. 6
}

\footnotetext{
6 Disponível em http://w2.vatican.va/content/leo-xiii/pt/encyclicals/documents/hf 1-xiii_enc 15051891_rerum- novarum.html.
} 
É preciso mencionar que desde o surgimento da Igreja Católica, diversas Encíclicas foram publicadas e que tais encíclicas não possuem a natureza jurídica de uma lei ou norma constitucional. Entretanto, pela força que o catolicismo possuía - e, em menor escala, ainda possui - fez com que os Estados começassem a se preocupar com os direitos nelas constantes.

E não poderia ser diferente com o Estado brasileiro. A Constituição Federal de 1988 atribuiu aos Estados a competência para a organização da justiça e estabeleceu no art. 125, § $6^{\circ}$, a possibilidade de descentralizar o Tribunal de Justiça, através de Câmaras regionais, com o intuito de levar a justiça mais perto do povo.

Sabe-se que a justiça é dinâmica, e por tal característica, deve o Estado efetivar meios para que o Poder Judiciário se aproxime do cidadão, principalmente daquele menos favorecidos, minoria na sociedade. Neste ponto, importante a implementação de programas, como o chamado Justiça no Bairro, que resolve situações simples sem a necessidade dos cidadãos buscarem a tutela do Ministério Público ou Defensoria Pública.

No Estado do Paraná, a cargo da Desembargadora Joeci Machado Camargo, o Programa atendeu, somente no ano de 2014, 21 cidades do Estado levando aos jurisdicionados de cada um destes Municípios celeridade nas demandas já existentes, bem como solução imediata a diversas causas, como por exemplo, decretação de divórcio, realização de diversas perícias médicas, dentre outras atividades. ${ }^{7}$ É realizado, ainda dentre as atividades propostas pelo denominado "Justiça no Bairro", a celebração da união civil. No último evento de 2014, realizado na cidade de Curitiba, no Estado do Paraná, no dia 07 de dezembro, o programa Justiça no Bairro, que conta com a colaboração do SESC Cidadão, realizou a união de 800 casais na Arena da Baixada ${ }^{8}$. O projeto citado, que é voltado para as famílias que possuam renda máxima de até três salários mínimos, absorve os processos litigiosos já distribuídos, inclusive aqueles provenientes da defensoria pública, núcleos de prática jurídica, e alcança um resultado de até $70 \%$ de conciliação, o que leva a uma maior efetividade e, na outra parcela não conciliada, uma melhor orientação.

\footnotetext{
7 Disponível em <https://www.tjpr.jus.br/justica-no-bairro/-/asset_publisher/3Rlw/content/divulgacao2014/399009?redirect=https\%3A\%2F\%2Fwww.tjpr.jus.br\%2Fjustica-nobairro\%3Fp_p_id\%3D101_INSTANCE 3Rlw\%26p_p_lifecycle\%3D0\%26p_p state\%3Dnormal\%26p_p_mode \%3Dview\%26p_p_col_id\%3Dcolumn-2\%26p_p_col_count\%3D1>.

8 Disponível em <http://www.sescpr.com.br/2014/12/justica-no-bairro-sesc-cidadao-celebra-uniao-civil-de-800- casais-na-arena-dabaixada/>.
} 
Pode-se citar, ainda, que, por ser itinerante, o Justiça no Bairro também acaba por absorver a denominada "demanda reprimida", o que possibilita ao juiz da comarca o agendamento de diversas audiências simultâneas de processos em trâmite, com o intuito de destrancar a pauta, garantindo aos jurisdicionados a celeridade processual determinada pela Constituição Federal. Saliente-se que o atendimento também se estende aos pedidos iniciais litigiosos, já que advogados e núcleos de prática jurídica se colocam à disposição para as novas causas.

Programas como o explanado faz com que o direito ao acesso à justiça possa ser efetivado, já que traz resultados expressivos e de imediato. De um modo geral, percebe-se que a população possui receio de buscar o Judiciário, ingressar no ambiente gélido dos fóruns. Assim, deve o Poder Judiciário demonstrar ao cidadão que se encontra totalmente estruturado para colocar fim à lide e efetivar o acesso à justiça. Vale ressaltar que o programa citado é um dos exemplos, dentre outros tantos espalhados pelo país, de efetividade dos direitos constitucionais, dentre eles o de efetivo acesso à justiça. Todavia, há muito que se fazer. É preciso maior empenho não só dos Poderes da República, mas de todos os segmentos da sociedade e dos próprios cidadãos, como um todo, na busca pela efetividade dos direitos assegurados pela Constituição Federal.

\section{CONCLUSÃO}

O direito ao acesso à justiça não significa somente dar ao cidadão a possibilidade de acesso a um julgamento. Não se trata mais de possibilitar a alguém uma sentença de mérito como resolução de seu problema. Hoje o acesso à justiça é muito mais abrange do que simplesmente abrir as portas do Poder Judiciário ao povo.

Pode-se afirmar que há acesso à justiça quando se possibilita a dispensa do pagamento das custas processuais, ou ainda, quando há a nomeação de um advogado dativo para a defesa dos interesses de determinado indivíduo. Entretanto, tal acesso é ineficaz quando, por exemplo, a defesa nomeada se mostra deficiente.

Se quando um indivíduo considerado pobre é atendido de modo diferente ou possui uma defesa técnica inferior àquela realizada para um indivíduo com melhores condições financeiras, pode-se afirmar que o Estado falhou em sua proteção e que não houve efetivo acesso à justiça. Neste ponto verificou-se no decorrer do presente trabalho toda a evolução histórica 
que o "acesso à justiça" sofreu nas últimas décadas. Não se pode permitir que, com a vigência da atual constituição, direitos, como é o caso citado, sejam desrespeitados e que os cidadãos à margem da sociedade sejam tolhidos dos seus anseios e garantias fundamentais.

Como visto, há inúmeros movimentos e projetos desenvolvidos por diversos segmentos da sociedade e, também, pelo próprio Poder Judiciário, tentando minimizar a prática evidente da exclusão processual daqueles considerados pobres. Todavia, percebe-se que ainda é pouco, há muito a se fazer, sem que, contudo, novos direitos sejam criados. A Constituição Federal garante amplo acesso aos direitos fundamentais, sem necessidade de inclusão em seu texto de outros novos direitos. O que é preciso é atuação direta do Estado na efetivação daqueles direitos que ali já residem. É preciso que o acesso à justiça prometido pelo constituinte seja visualizado amplamente para que possa ser sinônimo de acesso a uma ordem jurídica efetivamente justa. 


\section{REFERÊNCIAS}

ABRANCHES, Sérgio Henrique. Política social e combate à pobreza: a teoria da prática. Rio de Janeiro: Jorge Zahar editor, 1998.

BARBOSA, Rui. Oração aos moços. Rio de Janeiro: Fundação Casa de Rui Barbosa, 1997.

BOBBIO, Norberto; MATTEUCCI, Nicola; PASQUINO, Gianfranco. Dicionário de política. Brasília: UNB, 2004.

CAPPELLETTI, Mauro; GARTH, Bryant. Acesso à Justiça. Porto Alegre: Fabris, 1998.

CANOTILHO, J. J. Gomes. Direito constitucional e teoria da constitucional. Coimbra: Almedina, 2003.

DEMO, Pedro. Pobreza Política: a pobreza mais intensa da pobreza brasileira. Campinas: Armazém do Ipê, 2006.

DINAMARCO, Cândido Rangel. A instrumentalidade do processo. São Paulo: Editora Revista dos Tribunais, 1987, p. XIV.

GALLASSI, Almir. O acesso a justiça como garantia dos direitos fundamentais das minorias sociais. IN Acesso à Justiça: uma perspectiva da democratização da administração da justiça nas dimensões social, política e econômica/Dirceu Siqueira, Flávio Luis de Oliveira, organizadores. São Paulo: Boreal Editora, 2012.

GARCIA, Ronaldo Coutinho. Iniquidade social no Brasil: uma aproximação e uma tentativa. Brasília: IPEA, 2003, p. 10. Disponível em < http://www.ipea.gov.br/portal/images/stories/PDFs/TDs/td_0971.pdf>.

GONÇALVES, Vinícius José Corrêa. Tribunais Multiportas: em busca de novos caminhos para a efetivação dos direitos fundamentais de acesso à justiça e à razoável duração dos processos. 2011. 225 f. Dissertação (Mestrado em Ciência Jurídica) - Universidade Estadual do Norte do Paraná, Jacarezinho, 2011.

HESS, Heliana Coutinho. Acesso à justiça por reformas judiciais. Campinas: Milennium, 2004.

LYRA, Doreodó Araújo. Desordem e Processo: estudos sobre o direito em homenagem a Roberto Lyra Filho. Porto Alegre: Sérgio Fabris Editor, 1986.

MARTINS, Daniela Dias Graciotto. O acesso à justiça frente às crises do direito, da administração da justiça e do juiz. IN Acesso à Justiça: uma perspectiva da democratização da administração da justiça nas dimensões social, política e econômica/Dirceu Siqueira, Flávio Luis de Oliveira, organizadores. São Paulo: Boreal Editora, 2012. 
MORAIS, José Luis Bolzan de. Mediação e arbitragem: alternativas à jurisdição. Porto Alegre: Livraria do Advogado, 1999.

REALE, Miguel. Lições Preliminares de Direito, 27ª ed. São Paulo: Saraiva, 2002.

ROCHA, Sonia. Pobreza no Brasil: afinal, de que se trata? Rio de Janeiro: Editora FGV, 2003.

SILVA, Adriana dos Santos. Acesso à justiça e arbitragem: um caminho para a crise do judiciário. Barueri: Manole, 2005.

SOUZA, Gelson Amaro; SOUZA FILHO, Gelson Amaro de. Processo e Acesso à Justiça. IN Acesso à Justiça: uma perspectiva da democratização da administração da justiça nas dimensões social, política e econômica/Dirceu Siqueira, Flávio Luis de Oliveira, organizadores. São Paulo: Boreal Editora, 2012. 